\title{
Recurrent hemoptysis \\ - a complication associated with an azygos lobe
}

\author{
Tatiana Denega MD, Suzanne Alkul BS, Ebtesam Islam MD, PhD, Raed Alalawi MD
}

\begin{abstract}
The azygos lobe, also commonly referred to as an accessory lobe of the azygos vein, is located at the apicomedial portion of the right lung and is separated from the remainder of the upper lobe by a fissure. It usually has no significant clinical implications and is an incidental finding in radiographic studies. We report a patient with recurrent hemoptysis who had no obvious explanation for bleeding. At surgery the posterior segment of the right upper lobe was tucked behind and compressed by the azygos lobe. This suggested that the recurrent bleeding was due to the azygos lobe.
\end{abstract}

Key words: azygos lobe, hemoptysis, chest radiograph

\section{INTRODUCTION}

The azygos lobe is usually recognized as having no significant clinical implications and is an incidental finding in radiographic studies (Figure 1). We report a case of recurrent hemoptysis in a patient with no obvious source of bleeding. During a subsequent surgical intervention the thoracic surgeon noted that the azygos lobe caused extrinsic compression of the posterior segment of the right upper lobe, and this likely caused the recurrent bleeding.

\section{CASE}

A 66-year-old Hispanic man was admitted to University Medical Center with recurrent hemoptysis with bright red blood for the past two years. His

Corresponding author: Tatiana Denega MD

Contact Information: tatiana.denega@ttuhsc.edu DOI: 10.12746/swrccc2015.0311.146

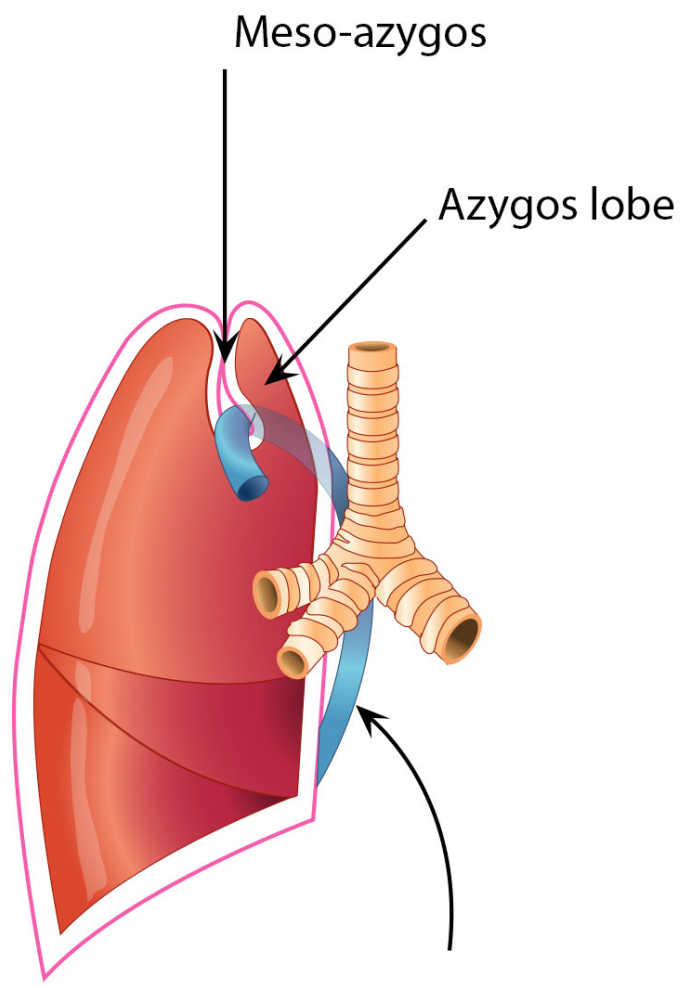

Azygos vein

Figure1: Azygos lobe formation. 
physical examination showed no abnormal findings. Computed tomography of the chest revealed an azygos lobe in the right lung that was smooth and regular in shape; no other pathological changes were found (Figure 2). Fiberoptic bronchoscopy showed a blood clot in the apical segment of the right upper lobe. Hemostasis with the local administration of thrombin and endobronchial sealing was attempted but unsuccessful. A thoracic angiogram showed no dilated bronchial arteries. Bronchial artery embolization was attempted but was not successful. A surgical intervention was pursued. It was found that the posterior segment of the right upper lobe was tucked behind and compressed by the azygos lobe and was grossly hemorrhagic. Segmentectomy was performed. Histopathology showed a large number of macrophages with hemosiderin pigment and fresh hemorrhage in the alveoli. No tumor, infection, or vascular malformations were found. The alveolar basement membrane was negative for $\lg \mathrm{A}, \lg \mathrm{G}, \lg \mathrm{M}$, and $\mathrm{C} 3$. The patient had no postoperative complications, and his symptoms resolved.

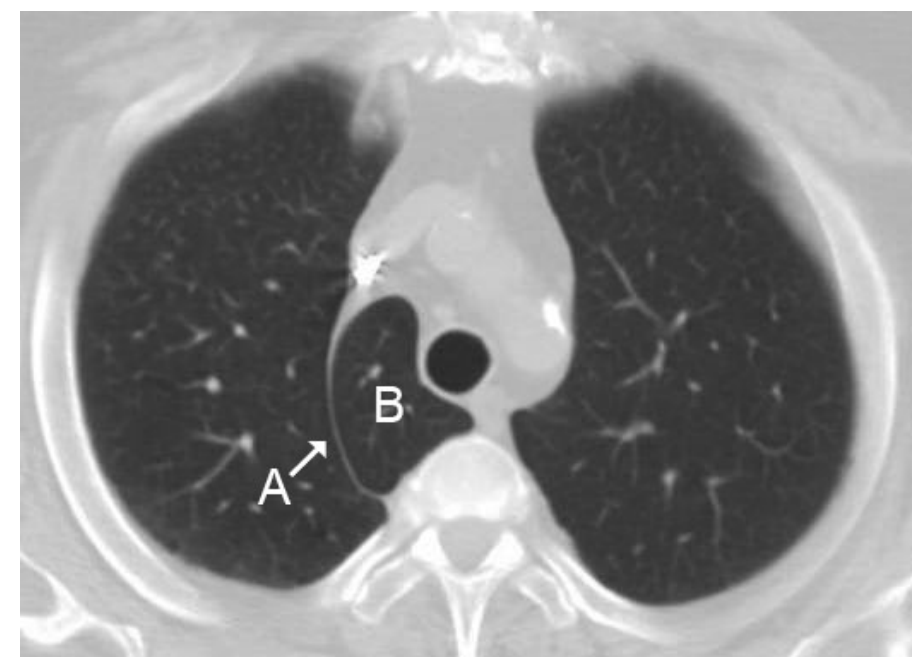

Figure2: CT scan of the chest depicts the fissure (A) as a curved/C-shaped line. It originates at the area of right brachiocephalic vein and SVC and ends at the lateral side of the vertebral bodies and the azygos lobe (B).

\section{Discussion}

The azygos lobe, also commonly referred to as an accessory lobe of the azygos vein, is located at the apicomedial portion of the right lung and is separated from the remainder of the upper lobe by a fissure (Figure 1). A convex shaped fissure is created by the course of the vein bearing towards the medial side of the right lung to join with the superior vena cava. Its formation is the result of an unusual embryogenic migration of the posterior cardinal vein, which is a precursor of the vena azygos. Instead of sliding over the lung medially, the vein invaginates into the parenchyma of the lung and becomes enveloped by layers of pleural folds, forming a mesentery-like structure, also called "meso-azygos". 1,2 Further migration into the lung as it passes towards the right hilum creates a convex semicircular fissure with the vein located at the base of the fissure. ${ }^{1,2}$

The azygos lobe is generally an incidental finding in radiologic imaging studies. It is usually benign and asymptomatic and found in a small number of patients. X-ray imaging identifies the lobe as a comma-shaped or curved linear shadow in the paramediastinal region of the right lung; it terminates at the level of the second costal cartilage. The azygos vein is represented as a dense shadow at the end of the linear curve in folds of meso-azygos. The pathway of the vein within the lung is subject to individual variation, and this defines the position of the fissure within the apex of the upper lobe. The contour of the azygos lobe can be visualized easily, if the pleural folds of the fissure are thickened or widened.

Diagnosing the azygos lobe may be complicated by morphologic variants of the fissure, physiological changes in the size of the vein, and the projection of additional shadows within the lobe which may be misinterpreted as scar tissue, a calcified area of a post-infectious process, or as a malignant tissue or nodule. ${ }^{1,2}$ Widening of the vein due to an increase of blood pressure within the azygos venous system can occur in congenital malformations of the inferior vena cava (IVC), such as aplasia of its inferior part or ab- 
dominal segment, and in some acquired conditions, such as constriction of the IVC by enlarged lymphatic nodes, invasive malignancy, or collagenous tissues, and create a false impression of an intraparenchymal pathology or mediastinal mass.

The azygos vein may undergo physiological variations, reflected by changes in the size of its shadow and its position in the imaging studies. Expiration, the Valsalva maneuver, or the upright position decreases venous return to the heart and hence the size of the vein. Inspiration or supine position causes an increase in the blood flow return and, therefore, increases the size of the vein and its shadow. Changes in the intrathoracic pressure may result in the "empty azygos fissure" phenomenon, in which the medial displacement of the azygos vein occurs after the re-expansion the collapsed lung, secondary to pneumothorax or pleural effusion as well as a shortened meso-azygos.

In rare cases, the azygos vein may undergo aneurysmal changes. In idiopathic or congenital cases, these aneurysms are commonly located in the arch of the vein. They remain asymptomatic or may be accompanied by a "pressure-like" or "tightness" sensation within the chest. ${ }^{6-10}$ On the chest $x$-ray the enlarged vein may be represented by a round or oval paratracheal shadow with a smooth surface or outline. ${ }^{14}$ An untreated azygos vein aneurysm can predispose the patient to the risk of rupture, thrombosis, or pulmonary embolism.

As in all lung tissue, some pathologic processes can originate in the azygos lobe, including bullous or bronchiectatic changes, pneumonia, and tuberculosis. ${ }^{2,11}$ It seems likely that pleural folds of mesoazygos serve as a barrier ${ }^{2}$ to the dissemination of the infection or malignant cells. For example, in patients with pulmonary tuberculosis dissemination of the tuberculous infection into the azygos lobe is uncommon. ${ }^{10}$ In patients with adenocarcinoma of the lung in the azygos lobe, histologic analysis of regional lymph nodes revealed no metastatic disease.

\section{Conclusions}

The incidental finding of an azygos lobe is usually clinically unimportant and does not require additional evaluation. However, as in any other region of the lung, some pulmonary disorders may develop within this lobe and require detailed evaluation with CT imaging studies. In our patient, intrasurgical evaluation of the lung revealed that the posterior segment of the right upper lobe was tucked behind and compressed by the azygos lobe. Histopathological analysis revealed hemorrhagic changes within the resected segment. This case suggests that the recurrent hemoptysis could be due to the azygos lobe, and in the absence of an alternative diagnosis for hemoptysis, the azygos lobe should be considered as a possible cause. Colby has discussed problems with diagnosis in some patients with significant pulmonary hemorrhage in a review article. ${ }^{15}$

Author Affiliation: All authors work in the Department of Internal Medicine at Texas Tech University Health Sciences Center in Lubbock, TX. Tatiana Denega is a resident, Suzanne Alkul is a medical student, Ebtesam Islam is a fellow in Pulmonary-Critical Care, and Raed Alalawi is a faculty member in Pulmonary and Critical Care.

Received: 04/27/2015

Accepted: 06/18/2015

Reviewers: Eman Attaya MD

Published electronically: 07/15/2015

Conflict of Interest Disclosures: none 


\section{REFERENCES}

1. Mata J, Cáceres J, Alegret X, Coscojuela P, De Marcos JA. Imaging of the azygos lobe: normal anatomy and variations. $A J$ $R$ 1991; 156: pp 931-937.

2. Felson B. The azygos lobe: its variation in health and disease. Semin Roentgenology 1989; 24 (1): pp 56-66.

3. Dudiak CM, Olson MC, Posniak HV. Abnormalities of the azygos system: CT evaluation. Semin Roentgenology 1989; 24(1): pp.47-55.

4. Lenoir V, Kohler R, Montet X. The empty azygos fissure. $J$ Radiol Case Reports 2013; 7 (4): pp 10-15.

5. Betschart T, Goerres GW. Azygos lobe without azygos vein as a sign of previous iatrogenic pneumothorax: two case reports. Surg Radiol Anat 2009 Aug; 31(7):pp 559-562.

6. Icard P, Fares E, Regnard JF, Levasseur P. Thrombosis of an idiopathic saccular azygos aneurysm. Europ $J$ Cardio-Thorac Surg 1999; 15(6): pp 870-872.

7. Poll LW, Koch JA, Finken S, Lurz K, Habersang K, Mödder U. Azygos continuation syndrome with aneurysm of the azygos vein: CT and MR appearances. J Computer-assisted Tomography 1999; 23(1): pp 19-22.

8. Kurihara Y, Nakajima Y, Ishikawa T. Case report: saccular aneurysm of the azygos vein simulating a paratracheal tumor. Clinical Radiology 1993; 48: pp 427-428.

9. Watanabe A, Kusajima K, Aisaka N, Sugawara H, Tsunematsu. Idiopathic saccular azygos vein aneurysm. Ann Thorac Surg 1998; 65: pp 1459-1461.

10. Ko S-F, Huang C-C, Lin J-W, Lu H-I, Kung C-T, Ng S-H, Wan Y-L, Yip H-K. Imaging features and outcomes in 10 cases of idiopathic azygos vein aneurysm. Annals Thorac Surg 2014; 97(3): 873-878.

11. Underwood EA, Tattersall N. The accessory lobe of the azygos vein: a record of fourteen cases, with special reference to heredity as an etiological factor, and to pathological features of the condition. Tubercle 1933; 15(1): pp 1-12.

12. Shakir HA. Removal of aberrant azygos lobe containing positron emission tomography positive nodule with the use of videoassisted thoracic surgery. Intern J Surg Case Reports 2014; 5(2): pp 95-96.

13. Arai $H$, Inui $K$, Kano $K$, Nishii $T$, Kaneko $T$, Mano H, Sasaki T, Masuda M. Lung cancer associated with an azygos lobe successfully treated with video-assisted thoracoscopic surgery. Asian J Endoscopic Surg 2012; 5(2): pp 96-99.

14. Fukuhara S, Montgomery M, Reyes A. Robot-assisted azygos lobectomy for adenocarcinoma arising in an azygos lobe. Interactive Cardiovas Thorac Surg 2013; 16(5): 715-717.

15. Colby TV, Fukuoka J, Ewaskow SP, Helmers R, Leslie KO. Pathologic Approach to Pulmonary Hemorrhage. Ann Diagn Pathol 2001; 5: 309-319. 